\title{
Summary updates September 2015 for vultures and VSG activities
}

Plenty of headlines recently, including publicity highlighting the extent of African vulture declines, and the lack of progress in Europe with EU not yet stopping diclofenac licensing there. On the positive side, the Indian Government has banned large vials of human diclofenac and the $5^{\text {th }}$ September 2015 saw the celebration of the 7th International Vulture Awareness Day with 125 organisations worldwide registering events on the website www.vultureday.org. National Geographic's Great Nature Project is helping to raise awareness about Vulture Awareness Day and started a vultures photo collection with promotion from early September. There are also new moves to develop a multi-species action plan for all vultures under the CMS which should help raise the profile and attract resources although this is at an early stage. We take the opportunity to clarify on red-listing and the role of VSG and its members.

\section{Diclofenac in Europe}

Following the EU public consultation in late 2014 and the deliberation of its own European Medicines Agency (EMA) that clearly recognised that diclofenac poses a threat to European vultures, it listed a number of potential solutions: from banning the product to the adoption of risk mitigation measures. But the EU commission has unfortunately decided not to start a referral process to ban diclofenac. Instead it is pressing for the adoption of those risk-mitigating measures that would, theoretically, prevent contaminated carcasses from entering the vulture food chain. The EU is now discussing with member states to review their position regarding those mitigating measures. This is clearly the easiest, but less safe option, and it is only a matter of time before the first Eurasian Griffons are found killed by this veterinary drug in Europe. The emphasis therefore becomes developing a system for finding vulture carcasses and getting them reliably analysed. The issue was highlighted for IVAD with press releases (See \#banvetdiclofenac! \& www.4vultures.org for more)

\section{European roundup}

Some good news - confirming the continent is now the stronghold for vultures in the Old World, after years 
of conservation investment and projects there. Bearded Vultures bred for the first time in the wild in Andalusia (Spain) for $30+$ years, only 9 years after the reintroduction project started there, while Eurasian Griffons also bred for the first time in 70+ years in area north of Sophia in Bulgaria (in the Balkans) following the reintroduction project there [see article this issue - Ed.]. The Cinereous Vulture reintroduction project in France is also going well, and this year saw another successful breeding season for the Bearded Vulture in the Alps the species is now firmly established there (32 pairs). A total of 16 young Bearded Vultures were reintroduced by the Vulture Conservation Foundation (VCF) with respective local partners in three programs. The one negative is for Egyptian Vulture, which continues to decline almost everywhere, including in Europe, so the major July workshop in Sofia, organised by CMS and the LIFE Return of the Neophron project, to develop an action plan for the entire eastern flyway was very welcome. More recently, a number of captivebred Egyptian Vultures have been released in southern Italy in an experiment to test how well they survive and the viability of the method. See news about all these projects at www.4vultures.org/news

\section{African roundup}

The second Pan-African Vulture Summit is now confirmed in conjunction with the Pan-African Ornithological Congress in Dakar, Senegal from 17-21 October 2016. There was also a 'vulture seminar' at VulPro in South Africa 26-28 October 2015 and the BirdLife African Partnership meeting (also October 2015) had a vulture session where the partners discussed their potential actions for vultures and these will then feed in to the PanAfrican Summit. A Namibian workshop on poisoning and vultures took place in the Caprivi region in mid-February 2015. BirdLife Zimbabwe convened a Vulture Action Planning Workshop in March 2015 in collaboration with the Zimbabwe Parks Management Authority. The workshop developed a national vulture action plan and was attended by academic and conservation organisations from the region as well as relevant government departments. Zimbabwe Vulture Working Group was formed to initiate implementation, which had its first meeting in June and is already 
active. The BirdLife Africa Secretariat (Nairobi) is appointing a vulture conservation officer to start from November to help lead and coordinate vulture work across Africa.

Three major papers on Africa's vultures have recently been published and they have generated considerable attention from the press thus putting African vulture declines and threats to populations on a global stage. A collaborative paper on the declines and threats to Africa's vultures was published in Conservation Letters in June. In response BirdLife has uplisted White-headed, Hooded, Whitebacked, and Rüppell's Vultures to Critically Endangered, and Lappetfaced and Cape Vultures to Endangered. A paper on the trade in vultures and other raptors for bushmeat and fetish in West and Central Africa was published in Oryx in August. A paper analysing Bearded Vulture movements to inform placement of wind turbines was published in the $J$ of App Ecology in June. The issue of energy development looms large in Africa, with major impacts expected for vultures. The Peregrine Fund and partners completed shooting of a short feature film in Maa called Orng'aam (Empty Skies) about the importance of vultures in the ecosystem. This film will be shown across the Mara landscape to villages with the aim of changing people's attitudes about vultures, wildlife and poisoning. The Kenya Wildlife Service set up a taskforce to draft a plan to reintroduce Bearded Vultures (again), though no funding is available at present. Talks are also ongoing between members of the taskforce and colleagues in South Africa towards a possible collaboration. Repeats of Thiollay's earlier surveys in Ethiopia were carried out in January 2015 with worrying trends for all vulture species, Egyptian Vulture in particular. A feature story focused on African vultures is scheduled for publication in the January 2016 issue of National Geographic magazine. Finally, a publicity stunt by BirdLife South Africa for vultures - discovery of the new species, the 'Tuluver' attracted 300,000 visits to the first Facebook post alone - a novel if slightly controversial approach which certainly attracted attention! Well worth watching the explanatory video if you've not seen it!

\section{Asian roundup}

The major and very positive news is that large vials of human diclofenac 
were legally banned in India by the Health Ministry with immediate effect in August, undoubtedly the biggest step for vulture conservation since the veterinary formulation bans in 2006 and 2010. This is a result of five years of lobbying by BNHS and SAVE and means that the huge quantities of diclofenac still being used to treat cattle (albeit at $20 \%$ the levels used prior to the ban) will hopefully be reduced further as it becomes less convenient and also more expensive in only $3 \mathrm{ml}$ ampoules rather than ten times that. BirdLife Cambodia was also formalised as the $14^{\text {th }}$ member of SAVE www.save-vultures.org

\section{North America}

In Arizona and Utah USA, a record number (91\% \& 84\% respectively) of big game hunters in the California Condor's core range were voluntarily using non-lead ammunition or removing lead-infected gut piles from the field. Despite this success, annual trapping and testing of condors from this population revealed a slightly increased percentage of birds with toxic bloodlead levels from the previous year. Fifty-five of the 73 condors tested over the winter and early spring showed unsafe levels of lead in their blood. Nearly one-third of those birds had extreme, life-threatening toxicity levels. Of the 30 documented cases of lead-caused death in condors over the years, 21 contained evidence of ammunition in their gut, suggesting the birds consumed animals that were shot with various types of ammunition. Condor reintroduction partners are, following new evidence, expanding voluntary lead reduction efforts towards new groups including small game, bird and varmint hunters, and those who dispatch injured animals, e.g. ranchers or law enforcement agencies. In addition to the ongoing lead-reduction efforts, work with Native American tribes now incorporates key tribal lands. The recovery efforts are carried out by federal, state, and private partners, including The Peregrine Fund, Arizona Game and Fish Department, U.S. Fish and Wildlife Service, Arizona Strip Field Office of the Bureau of Land Management, Grand Canyon and Zion National Parks, Utah Division of Wildlife Resources, and Kaibab and Dixie National Forests. For more on condors and lead, visit www.azgfd.gov/condor and www.peregrinefund.org/condor. Hawk Mountain Sanctuary continues analysis of home-range data for 48 satellite tracked Turkey Vultures 
breeding in Canada, the United States, and Argentina including one bird that has now been tracked for 11 years. In Pennsylvania, two additional devices were fitted to Black Vultures. Seasonal roadside counts of Turkey Vultures and California Condors in California were initiated in early 2015, with repeats planned for 2016 .

\section{South America}

A Regional Andean Condor Workshop took place in Lima, Peru 6-9 May 2015 (Higher Regional para la Conservación del Condor Andino). It was organised by the Servicio Nacional Forestal y de Fauna Silvestre (SERFOR-Peru), Wildlife Conservation Society (WCS), Peregrine Fund, and the Ministerio del Ambiente (MINAMPeru). Researchers and conservation managers from seven South American countries attended. Priority conservation areas for Andean Condors at a regional level were identified as well as Guidelines for the production of an Action Plan for in situ conservation of Andean Condors at the regional level. Discussions focused on standardised census and population monitoring methodology for application across the Andean countries. During the workshop, the Government of Peru completed and officially launched the Action Plan for the Conservation of the Andean Condor in Peru. The next meeting of this group will be in 2018 in Colombia.

In Argentine Patagonia, Andean condors and Turkey vultures were GPS tagged as part of two research projects from Comahue University, CONICET, Doñana Biological Station and Hawk Mountain Sanctuary. Condors were also GPS tagged in the NW Argentina, San Juan province, by Wisconsin University, CONICET and Comahue University. Worryingly during recent months several condors have been found dead or sick in Colombia, Peru, Bolivia, Chile and Argentina.

\section{Clarification on VSG role and Red List reviews from the Co-chairs}

The VSG, as part of its remit, has been approached to engage with the IUCN Red List Authority in terms of the conservation status of certain species and to express an opinion on behalf of the VSG and its members to influence decisions in this regard. The role of the VSG in this regard, in its concept document, is described as: "Support and advise BirdLife International (the official IUCN Red List authority on birds) to determine 
and regularly review the diverse nature, range of individual conservation status of all vulture opinions within, and geographical species for the IUCN Red List." The VSG endeavours to do this where relevant and has provided input on such matters on a regular basis in the past. However, the process of review allows for comment from individual specialists and experts to comment and provide substantive support for changes in the status of species. We would like to encourage our members to actively participate in these processes where possible as your individual input can make a substantial contribution. Due to the spread of its membership, the VSG cannot claim to speak on behalf of all of its members in this regard and we therefore encourage you to contribute as much as possible to this process on an individual basis. We will continue to forward announcements of reviews and deadlines associated with status reviews to our members as a matter of course and look forward to your continued contributions.

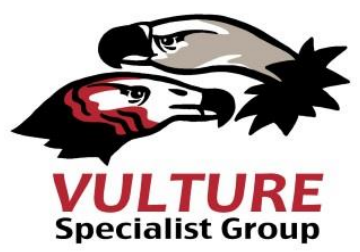

$* * * * * *$ 